\title{
ANALYSIS OF THE PHASE TRANSITIONS IN BNT-BT LEAD-FREE CERAMICS AROUND MORPHOTROPIC PHASE BOUNDARY BY MECHANICAL AND DIELECTRIC SPECTROSCOPIES
}

\begin{abstract}
In this work, the syntheses and characterization by mechanical and dielectric spectroscopies of (1-x) $\mathrm{Bi}_{0.5} \mathrm{Na}_{0.5} \mathrm{TiO}_{3-\mathrm{x}} \mathrm{BaTiO}_{3}(\mathrm{BNT}-100 \mathrm{xBT})$, with $\mathrm{x}=0.05,0.06$ and 0.07 , lead-free piezoelectric ceramics is reported. Ceramic samples of BNT-BT have been prepared by mixed-oxide method and then conventionally sintered. X-ray diffraction patterns of sintered samples, indicated for BNT-7BT the presence of tetragonal (P4mm) complex perovskite structure, whereas for BNT-5BT and BNT-6BT the samples exhibit a mixture of tetragonal (P4mm) and rhombohedral (R3c) crystalline phases, which reveal the presence of a morphotropic phase boundary (MPB) in the BNT-BT system. Measurements of internal friction, $\mathrm{Q}^{-1}$, and the storage modulus, E', as a function of temperature at various frequencies were carried out in a Dynamic Mechanical Analyzer (DMA), in the temperature range from $0^{\circ} \mathrm{C}$ to $600^{\circ} \mathrm{C}$. Dielectric profiles are recorded in the frequency range from $1 \mathrm{kHz}$ to $100 \mathrm{kHz}$ and the temperature range from room temperature to $475^{\circ} \mathrm{C}$. Mechanical loss spectra obtained for investigated compositions of BNT-BT samples showed different frequency-independent anomalies. Two main anomalies for BNT-5BT and BNT-6BT, observed around $100^{\circ} \mathrm{C}$ and $430^{\circ} \mathrm{C}$ were associated with the ferroelectric-antiferroelectric and antiferroelectricparaelectric phase transitions, respectively. The results obtained from mechanical loss measurements were supported by dielectric relaxation spectra. For BNT-7BT, outside the MPB, four different frequency-independent processes were observed.

Keywords: Lead-free piezoelectric ceramics, morphotropic phase boundary, phase transitions, mechanical spectroscopy, dielectric spectroscopy
\end{abstract}

\section{Introduction}

Lead-containing ferroelectric materials such as $\mathrm{Pb}\left(\mathrm{Zr}_{1-\mathrm{x}} \mathrm{Ti}_{\mathrm{x}}\right) \mathrm{O}_{3}(\mathrm{PZT})$ based ceramics (together with other toxic materials), have been widely used in numerous technological applications due to their excellent piezoelectric properties. However, the rapid growing amount of electronic residues and its incorrect elimination is becoming a major environmental problem. As a consequence of this global issue, since 2003 the European Union included the PZT in its legislation, joint with other dangerous substances that should be replaced with safe materials [1,2]. Furthermore, since 2006 the European Parliament adopted guidelines for waste electrical and electronic equipment (WEEE) [2] and the restriction of the use of certain hazardous substances in electrical and electronic equipment (RoHS) [1], to protect the human health and the environment through the substitution of hazardous substances with safer or safe materials. For these reasons, the interest in research on lead-free materials has recently increased, making it one of the current guidelines on research in ceramics [35]. With respect to the crystalline phases, the PZT shows in its phase diagram a region of morphotropic phase boundary (MPB) for compositions around $\mathrm{x}=0.48$, where the coexistence of the tetragonal and monoclinic or rhombohedral phases is observed. The existence of MPB, which is characterized by the coexistence of different structural phases for the same material composition, maximizes some properties of piezoelectric ceramics, such as dielectric permittivity, piezoelectric constant, and electromechanical coupling factors $[3,6]$. Therefore, the presence of MPB in lead-free solid solutions, becomes a fundamental factor. In recent years, the presence of MPB in different $\mathrm{Bi}_{0.5} \mathrm{Na}_{0.5} \mathrm{TiO}_{3}$-based solid solutions has been reported $[4,5,7,8]$. The $\mathrm{Bi}_{0.5} \mathrm{Na}_{0.5} \mathrm{TiO}_{3}-\mathrm{BaTiO}_{3}$ (BNT$\mathrm{BT})$ solid solution has been considered as a promising and one of the principal candidates for replacements of the PZT. However, some of its basic properties, such as the nature of the phase transitions and the relationship between the electric and mechanic responses $[9,10]$, mainly in the MPB region requires further investigation, which is the purpose of this study. The complementary and supplementary information obtained from loss spectra measured in mechanical spectroscopy [11,12] and dielectric spectroscopy $[13,14]$ is reported in this study.

\section{Experimental procedure}

The ceramic samples of $(1-\mathrm{x}) \mathrm{Bi}_{0.5} \mathrm{Na}_{0.5} \mathrm{TiO}_{3}-\mathrm{xBaTiO}_{3}$ (BNT-100xBT), with $\mathrm{x}=0.05,0.06,0.07$, have been prepared following the conventional mixed-oxide method. Stoichiometric amounts of $\mathrm{Bi} \mathrm{O}, \mathrm{BaCO}, \mathrm{Na}_{2} \mathrm{CO}_{3}, \mathrm{TiO}_{2}$ were mixed in isopropyl alcohol with zirconia grinding media for $24 \mathrm{~h}$ and calcined at $900^{\circ} \mathrm{C}$ for $3 \mathrm{~h}$. After calcination and further

* DEPARTMENT OF PHYSICS, FEDERAL UNIVERSITY OF SÃO CARLOS, CEP:13565-905, SÃO CARLOS- SP, BRAZIL

** SÃO CARLOS INSTITUTE OF PHYSICS, UNIVERSITY OF SÃO PAULO, CEP:13566-590, SÃO CARLOS- SP, BRAZIL

\# Corresponding author: psergio@df.ufscar.br 
milling and drying, polyvinyl butyral (PVB) was added as a binder to the calcined powder, which was isostatically pressed at $250 \mathrm{MPa}$ into disks with a diameter of $13 \mathrm{~mm}$ and bars with length of $30 \mathrm{~mm}$ and width of $8 \mathrm{~mm}$ and sintered in covered alumina crucibles at $1150^{\circ} \mathrm{C}$ for $3 \mathrm{~h}$. The sintered samples were then cut to $1 \mathrm{~mm}$ thickness and to dielectric characterization were electroded by platinum paint on both surfaces.

The crystalline structures of sintered ceramics were analyzed by X-ray diffraction (Shimadzu, model XRD-6000) with $\lambda_{\text {CuKa }}=1.54064 \AA$. The densities were measured by the Archimedes method.

The temperature dependence (from room temperature to $475^{\circ} \mathrm{C}$ ) of the dielectric permittivity of unpoled samples in the frequency range from $1 \mathrm{kHz}$ to $100 \mathrm{kHz}$ were measured employing an Impedance Gain Phase Analyzer (Solatron, FRA SI 1260 model) with an applied ac voltage of $50 \mathrm{mV}$ and with heating rate of $1^{\circ} \mathrm{C} / \mathrm{min}$.

The mechanical loss spectra, that is, internal friction, $\mathrm{Q}^{-1}$, and the storage modulus (proportional to Young's modulus), E', as a function of temperature were carried out using the three point bending method in forced oscillations, on bar-shaped specimens, in a Dynamic Mechanical Analyzer (PerkinElmer, DMA8000), in the temperature range from $0^{\circ} \mathrm{C}$ to $600^{\circ} \mathrm{C}$. The heating rate was $1^{\circ} \mathrm{C} / \mathrm{min}$ while the excitation frequency was in the range from $0.5 \mathrm{~Hz}$ to $20.0 \mathrm{~Hz}$.

\section{Results and discussions}

X-ray diffraction patterns of BNT-100xBT ceramics of sintered samples (at $1150^{\circ} \mathrm{C}$ for $3 \mathrm{~h}$ ), with $\mathrm{x}=0.05,0.06,0.07$, are shown in Fig. 1 where one can observe the evolution of the diffraction patterns with an increase of BT. Rietveld refinement of these, made by the GSAS code [15], permitted to establish that all prepared compositions crystallize in a complex perovskite structure without the presence of spurious phases. For BNT7BT composition the presence of a single tetragonal structure with space group P4mm and lattice constants $a=3.9051(2) \AA$ and $c=3.9054(4) \AA$ was determined. For BNT-5BT and BNT6BT compositions, Rietveld refinement permitted to establish that these compositions exhibit a mixture of tetragonal $(\mathrm{P} 4 \mathrm{~mm})$ and rhombohedral (R3c) crystalline phases, which reveal the presence of the morphotropic phase boundary (MPB) in the BNT-BT system. The lattice constants obtained for BNT-5BT are: rhombohedral phase $a=5.4953(3) \AA$ and $c=13.5509(13) \AA$, and tetragonal phase $a=3.9095(2) \AA$ and $c=3.9122(15) \AA$. The lattice constants for BNT-6BT are: rhombohedral phase $a=5.5505(13) \AA$ and $c=13.7507(9) \AA$, and tetragonal phase $a=3.8981(2) \AA$ and $c=3.9046(8) \AA$. The density obtained for prepared samples, after sintering, was measured by the Archimedes method. The relative densities with respect to the theoretical density calculated from refinement were $97 \%, 98 \%$, and $98 \%$ for BNT-5BT, BNT-6BT and BNT-7BT, respectively.
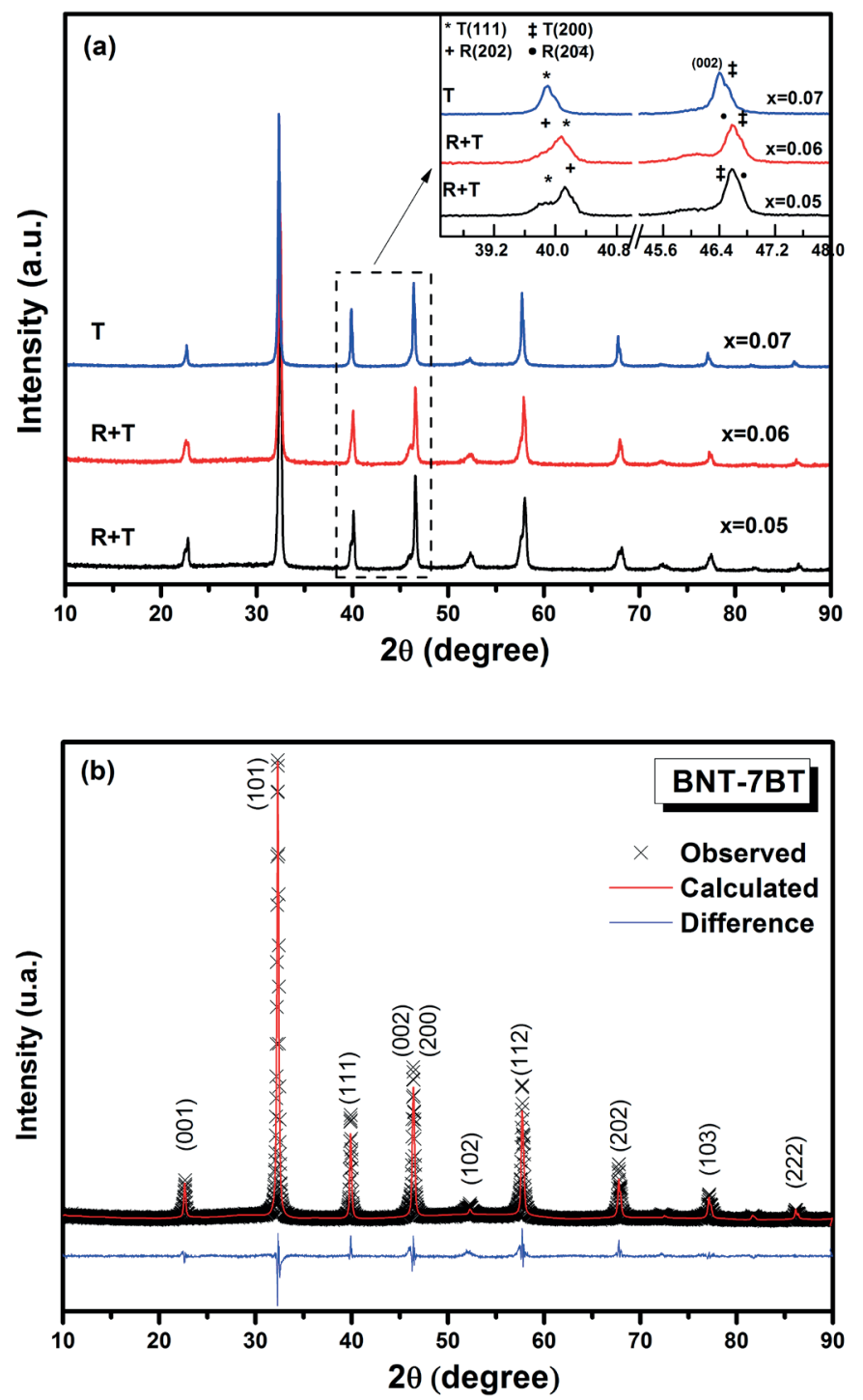

Fig. 1. X-ray diffraction patterns of BNT-100xBT ceramics of sintered samples, with $\mathrm{x}=0.05,0.06,0.07$. (a) Evolution of the diffraction patterns with increase of BT. $\mathrm{R}=$ rhombohedral, $\mathrm{T}=$ tetragonal. (b) Rietveld refinement for BNT-7BT

The variation of the real and imaginary parts of dielectric permittivity ( $\varepsilon$ ' and $\varepsilon$ ", respectively) as a function of temperature is shown in Figs. 2a, 3a and 4a. From these measurements, one can distinguish two temperature regions where different processes occur. The first region (between room temperature and $170^{\circ} \mathrm{C}$ ), $\mathrm{T}_{\varepsilon 1}$, shows maxima around $114^{\circ} \mathrm{C}, 105^{\circ} \mathrm{C}$ and $96^{\circ} \mathrm{C}$ (at $10 \mathrm{kHz}$ ) for BNT-5BT, BNT$6 \mathrm{BT}$ and BNT-7BT respectively. This observation indicate a relaxation process which can be related to ferroelectricantiferroelectric phase transition [16,17]. Moreover, BNT5BT and BNT-6BT also present anomalies associated with the rhombohedral-tetragonal structural phase transition [18]. The second region, around the temperature of maximum dielectric permittivity, $\mathrm{T}_{\varepsilon m}$, which occurs around $262^{\circ} \mathrm{C}, 275^{\circ} \mathrm{C}$ and $223^{\circ} \mathrm{C}$ for BNT-5BT, BNT-6BT and BNT-7BT respectively, shows any appreciable relaxation, this process occurs in a wide temperature range being characterized by different authors as a diffuse phase transition between the antiferroelectric and the paraelectric phases $[16,17]$. 


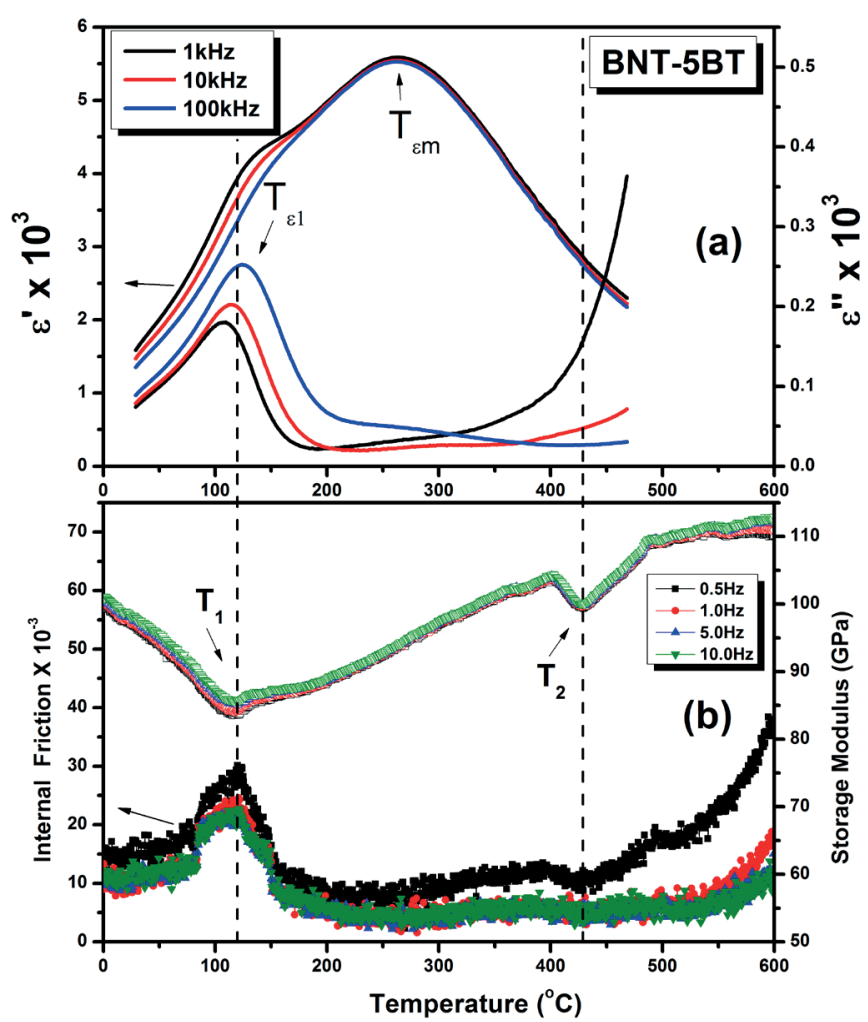

Fig. 2. Dielectric and anelastic measurements of BNT-5BT sample. (a) The real, $\varepsilon^{\prime}$, and imaginary, $\varepsilon^{\prime \prime}$, parts of dielectric permittivity as a function of temperature. (b) Internal friction and storage modulus as a function of temperature for different frequencies. (For interpretation of the references to color in this figure legend, readers are referred to the web version of this article.)

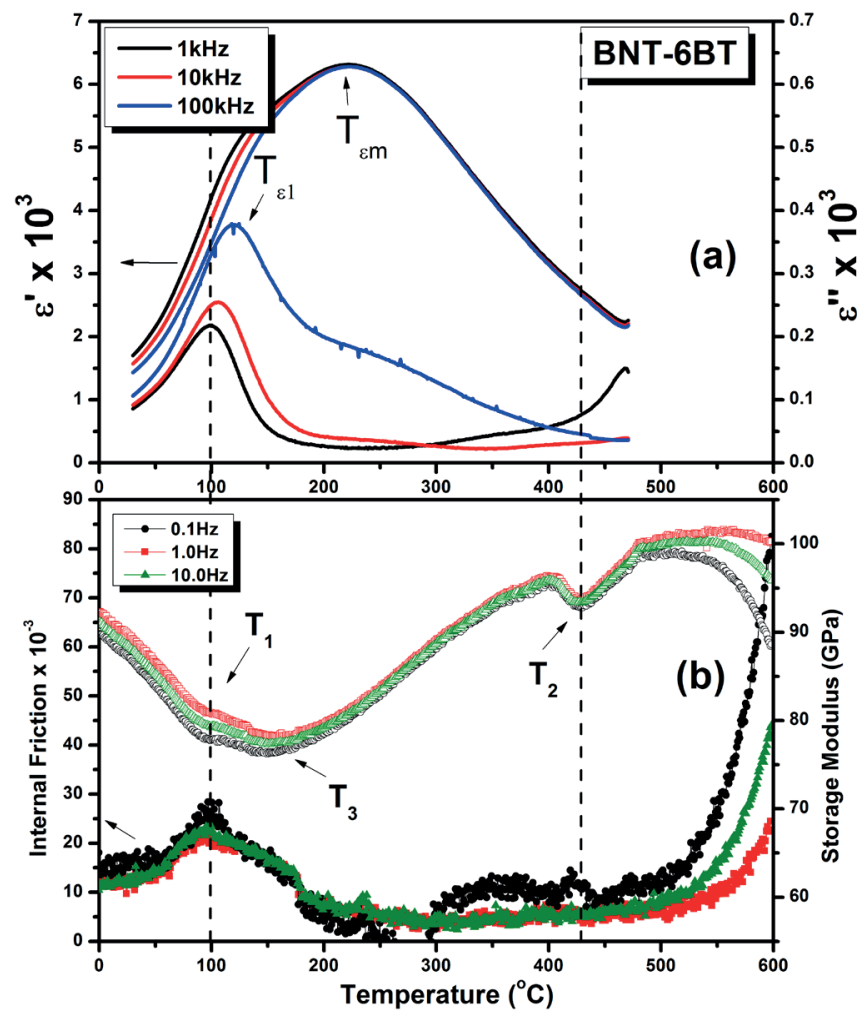

Fig. 3. Dielectric and anelastic measurements of BNT-6BT sample. (a) The real, $\varepsilon$ ', and imaginary, $\varepsilon$ ", parts of dielectric permittivity as a function of temperature. (b) Internal friction and storage modulus as a function of temperature for three different frequencies. (For interpretation of the references to color in this figure legend, readers are is referred to the web version of this article.)

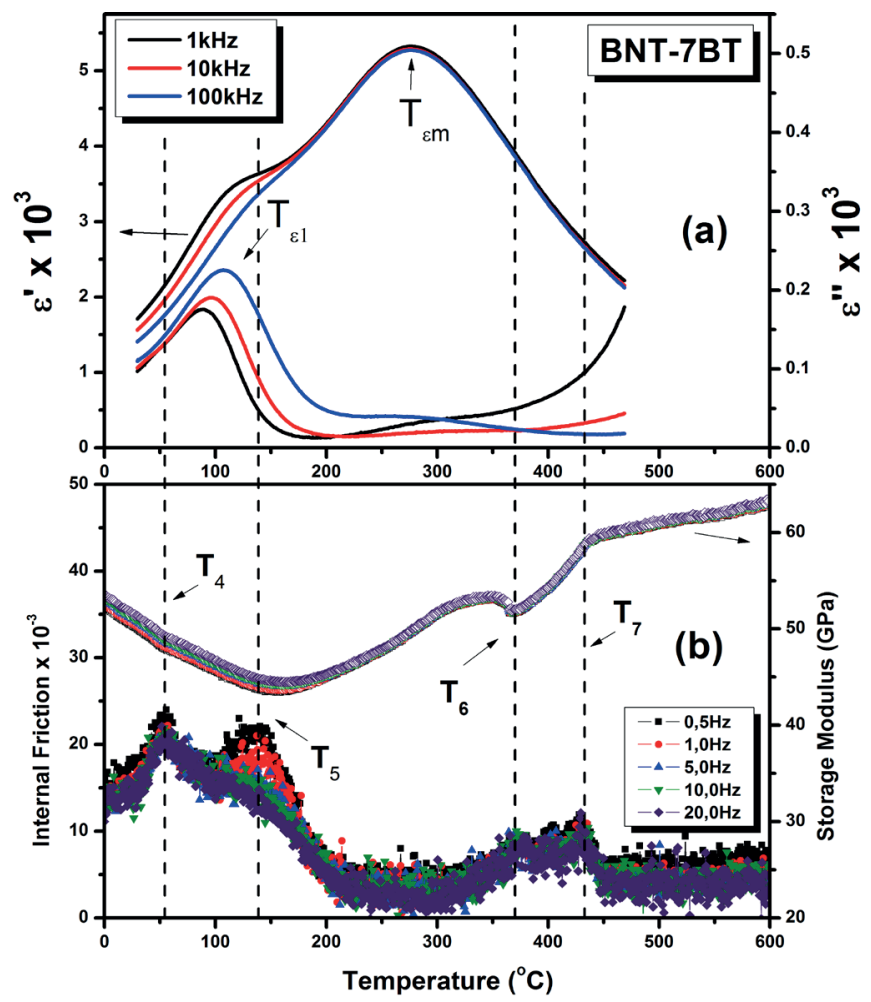

Fig. 4. Dielectric and anelastic measurements of BNT-7BT sample. (a) The real, $\varepsilon$ ', and imaginary, $\varepsilon "$, parts of dielectric permittivity as a function of temperature. (b) Internal friction and storage modulus as a function of temperature for five different frequencies. (For interpretation of the references to color in this figure legend, readers are referred to the web version of this article.)

Internal friction, $\mathrm{Q}^{-1}$, and storage modulus, $\mathrm{E}^{\prime}$, measured at different frequencies as a function of temperature, for the analyzed compositions (Figs. 2b, $3 \mathrm{~b}$ and $4 \mathrm{~b}$ ), indicate different anomalies. For BNT-5BT, the anomaly $\mathrm{T}_{1}$, observed around $120^{\circ} \mathrm{C}$, was associated with the structural phase transition from rhombohedral to tetragonal (R-T), and the anomaly $\mathrm{T}_{2}$, observed around $429^{\circ} \mathrm{C}$, was associated with the structural phase transition from tetragonal to cubic (T-C). For BNT-6BT the R-T (at $99^{\circ} \mathrm{C}$ ) and $\mathrm{T}-\mathrm{C}\left(\right.$ at $\left.429^{\circ} \mathrm{C}\right)$ phase transitions were preserved, also was distinguished another anomaly, T3, at around $149^{\circ} \mathrm{C}$ in the antiferroelectric tetragonal region that could be related with the incursion to the MPB, which means the presence of a tetragonal ferroelectric phase (TF) at room temperature and its evolution to a possible cubic or pseudocubic antiferroelectric phase (CAF) [18]. On the other hand, for BNT-7BT, which according to XRD analysis corresponds with a single tetragonal phase at room temperature, present four main frequency-independent anomalies, located at around $55^{\circ} \mathrm{C}, 140^{\circ} \mathrm{C}, 371^{\circ} \mathrm{C}$ and $431^{\circ} \mathrm{C}$. Further experimental and theoretical research is required for the better understanding of the physical processes involved in the development of the aforementioned anomalies. 


\section{Conclusions}

X-ray diffraction patterns shows the coexistence of rhombohedral and tetragonal phases, which is indicative of the MPB around $x=0.05$ and $x=0.06$. Mechanical loss spectra obtained for studied composition of the BNT-BT samples showed different frequency-independent anomalies. Two main anomalies for BNT-5BT and BNT-6BT, at around $100^{\circ} \mathrm{C}$ and $430^{\circ} \mathrm{C}$ are associated with the processes of ferroelectricantiferroelectric and antiferroelectric-paraelectric phase transitions, respectively, as observed in the reported dielectric spectra. For BNT-7BT, outside the MPB, four different frequency-independent processes were observed, but these processes should be carefully identified in future studies.

\section{Acknowledgments}

The authors would like to thank CNPq, CAPES and grant \#2012/08457-7 São Paulo Research Foundation (FAPESP), for the financial support.

\section{REFERENCES}

[1] EU-DIRECTIVE-2002/95/EC. Official Journal of the European Union 46, 19-23 (2003).

[2] EU-DIRECTIVE-2002/96/EC. Official Journal of the European Union 46, 24-38 (2003).

[3] S. Priya, S. Nahm, Lead-Free Piezoelectrics, Springer, New York, 2012.

[4] J. Rödel, W. Jo, K.T. P. Seifert, E.M. Anton, T. Granzow, D. Damjanovic, Perspective on the development of lead-free piezoceramics, Journal of the American Ceramic Society 92, 1153-1177 (2009).

[5] T. Takenaka, H. Nagata, Y. Hiruma, Current developments and prospective of lead-free piezoelectric ceramics, Japanese Journal of Applied Physics 47, 3787-3801 (2008).

[6] B. Jaffe, Piezoelectric Ceramics, London, Academic Press, 1971.

[7] T. Shrout, S. Zhang, Lead-free piezoelectric ceramics: Alternatives for PZT?, Journal of Electroceramics 19, 113-126
(2007).

[8] L. Martin-Arias, A. Castro, M. Algueró, Ferroelectric phases and relaxor states in the novel lead-free $(1-\mathrm{x})(\mathrm{Bi} 1 / 2 \mathrm{~K} 1 / 2)$ TiO3-xBiScO3 system $(0 \leq \mathrm{x} \leq 0.3)$, Journal of Materials Science 47, 3729-3740 (2012).

[9] O. Florencio, P.S. da Silva, J.A. Eiras, D. Garcia, E.R. Botero, Study of the Anelastic Behavior of PZT and PLZT Ferroelectric Ceramics, Defect and Diffusion Forum 326-328, 719-724 (2012).

[10] P.S. Silva Jr., O. Florêncio, E.R. Botero, J.A. Eiras, D. Garcia, Phase transition study in PLZT ferroelectric ceramics by mechanical and dielectric spectroscopies, Materials Science and Engineering. A, Structural Materials: properties, microstructure and processing, 521-522, 224-227 (2009).

[11] A.S. Nowick, B.S. Berry, Anelastic Relaxation in Crystalline Solids, Academic Press, 1972.

[12] S. Etienne, S. Elkoun, L. David, L.B. Magalas, Mechanical spectroscopy and other relaxation spectroscopies, Sol. St. Phen. 89, 31- 66 (2003).

[13] A.K. Jonscher, Dielectric Relaxation in Solids, Chelsea Dielectric Press, 1983

[14] L.V. Keldysh, D.A. Kirzhnitz, A.A. Maradudin (Eds.), The Dielectric Function of Condensed Systems, Elsevier Science Publishers, 1989.

[15] A.C. Larson, R.B. Von Dreele, General structure analysis system (GSAS), Los Alamos National Laboratory, Report LAUR 86-748 (2000).

[16] B. Parija, T. Badapanda, S. Panigrahi , T.P. Sinha, Ferroelectric and piezoelectric properties of $(1-\mathrm{x}) \mathrm{Bi} 0.5 \mathrm{Na} 0.5 \mathrm{TiO} 3-$ xBaTiO3 ceramics, Journal of Materials Science: Materials in Electronics 24, 402-410 (2013).

[17] J.H. Cho, S.C. Lee, L. Wang, H-G. Yeo, Y-S. Sung, M-H. Kim, T.K. Song, S.S. Kim, B.C. Choi, Dielectric properties and phase transitions in hetero-valent-ion-substituted (Bi0.5Na0.5) TiO3 ceramics, Journal of the Korean Physical Society 56, 457-461 (2010).

[18] F. Cordero, F. Craciun, F. Trequattrini, E. Mercadelli, C. Galassi, Phase transitions and phase diagram of the ferroelectric perovskite $(\mathrm{Na} 0.5 \mathrm{Bi} 0.5) 1-\mathrm{x}$ BaxTiO3 by anelastic and dielectric measurements, Physical Review B 81, 144124 (2010). 